\title{
Development of Methods for Gaseous Phase Geochemical Monitoring on the Surface and in the Intermediate Overburden Strata of Geological $\mathrm{CO}_{2}$ Storage Sites
}

\author{
Z. Pokryszka, A. Charmoille and G. Bentivegna \\ INERIS, Parc Technologique Alata, BP 2, 60550 Verneuil-en-Halatte - France \\ e-mail: zbigniew.pokryszka@ineris.fr - arnaud.charmoille@ineris.fr - gaetan.bentivegna@ineris.fr
}

\begin{abstract}
Résumé - Développement de méthodes de suivi géochimique en phase gazeuse à la surface et dans la couverture intermédiaire des sites de stockage géologique du $\mathbf{C O}_{2}-$ Les développements et les résultats présentés sont issus des travaux réalisés dans le cadre du programme Géocarbone-Monitoring cofinancé par l'Agence Nationale de la Recherche (ANR). Une partie importante de ce programme a porté sur des méthodes de suivi géochimique en phase gazeuse à la surface et dans la couverture intermédiaire des sites de stockage géologique du $\mathrm{CO}_{2}$. Le travail effectué par l'INERIS a été ciblé sur deux approches particulières, souvent préconisées comme incontournables dans la surveillance des futurs sites de stockage :

- une détection précoce (préalerte), au moyen de prélèvement et analyse de gaz au fond des forages de contrôle débouchant dans la couverture intermédiaire ;

- la détection et la quantification du flux gazeux de $\mathrm{CO}_{2}$ émanant du sol vers l'atmosphère.
\end{abstract}

Ces deux approches ont été successivement développées en laboratoire et ensuite appliquées et testées in-situ dans les conditions réelles, les plus proches possibles de celles de futurs sites de stockage. Elles présentent l'avantage d'assurer une mesure directe et de fournir les informations en temps réel sur la présence éventuelle ou au contraire sur l'absence de fuites du $\mathrm{CO}_{2}$.

Les essais réalisés sur un forage de $200 \mathrm{~m}$ de profondeur ont montré que la détection des fuites de $\mathrm{CO}_{2}$ traversant les couches de couverture intermédiaire était possible par un prélèvement et une analyse en continu du gaz s'accumulant au fond de forage. De bons résultats ont été notamment obtenus dans le cas de détection de petites bouffées de gaz arrivant au fond de sondage pouvant constituer le signe précurseur d'une fuite plus importante.

De même, un prélèvement et un transit de gaz à longue distance ont pu être réalisés jusqu'à $1000 \mathrm{~m}$ depuis le point de prélèvement sans provoquer une déformation et une dilution excessives du signal gazeux initial et ce même pour les fuites de faible ampleur.

Ces résultats permettent d'envisager à terme la mise en place d'un système relativement simple de détection et de suivi de fuites à travers les horizons géologiques intermédiaires. Ce dispositif sera composé pour une partie importante de capteurs industriels classiques disponibles dans le commerce.

La mesure directe du flux gazeux émanant du sol est l'une des méthodes les plus efficaces de contrôle et de suivi d'un site de stockage. La méthode de chambre à accumulation de l'INERIS a été améliorée pour la mesure de faibles flux de $\mathrm{CO}_{2}$. Elle permet maintenant de réaliser les mesures dans une large gamme 
de flux de $\mathrm{CO}_{2}$ allant du domaine des émissions très faibles de 0,05 à $0,2 \mathrm{~cm}^{3} \cdot \mathrm{min}^{-1} \cdot \mathrm{m}^{-2}$ jusqu'à un niveau de flux extrêmement forts de $3000 \mathrm{~cm}^{3} \cdot \mathrm{min}^{-1} \cdot \mathrm{m}^{-2}$ environ.

Ces caractéristiques métrologiques et opérationnelles ont été vérifiées et validées par les essais en laboratoire, sur un banc d'essais, mais aussi par les mesures sur le terrain dans les conditions réelles de sites naturellement émissifs du $\mathrm{CO}_{2}$. Ces essais ont montré une pleine maturité technique de la méthode pour une application pratique à la détection et au suivi des émissions de $\mathrm{CO}_{2}$ et de méthane à la surface du sol.

Les deux méthodes expérimentées sont désormais opérationnelles et disponibles pour être intégrées dans la stratégie de surveillance de futurs sites de stockage de $\mathrm{CO}_{2}$. Elles peuvent en effet être utilisées dans toutes les étapes de la vie d'un site de stockage : la reconnaissance du site, l'établissement de l'état initial, l'injection, la phase post-injection et le suivi résiduel après l'abandon.

\begin{abstract}
Development of Methods for Gaseous Phase Geochemical Monitoring on the Surface and in the Intermediate Overburden Strata of Geological $\mathrm{CO}_{2}$ Storage Sites - The developments and results presented in this paper are taken from the work carried out as part of the GeoCarbon-Monitoring project, which was partly funded by the French National Research Agency (ANR). An important part of this project covers methods for gas monitoring on the surface as well as within the cap rock of geological $\mathrm{CO}_{2}$ storage sites. The work undertaken by INERIS was targeted at two specific approaches which are often recommended as essential for the monitoring of future storage sites:

- early detection (pre-alert), based on the sampling and analysis of gas at the bottom of the dedicated boreholes which are drilled from the surface into the intermediate cap rock strata;

- the detection and quantification of the gaseous flux of $\mathrm{CO}_{2}$ released from the ground into the atmosphere.
\end{abstract}

These two approaches were developed in the laboratory successively and then applied and tested in-situ, under conditions that are as close as possible to those of the future storage sites. They offer the advantage of ensuring a direct measurement as well as providing real-time information on the presence or, on the contrary, the absence of $\mathrm{CO}_{2}$ leaks.

The tests undertaken on a 200 meter deep borehole have shown that the detection of $\mathrm{CO}_{2}$ leaks passing through the intermediate overburden strata was possible thanks to the continuous sampling and analysis of the composition of the gas which accumulated at the bottom of the borehole. In particular, the detection of small releases of gas emanating from the surrounding rock gave rise to a number of good results. These releases may be a precursor to a larger leak.

Likewise, it has been possible to take a sample and ensure the transit of gas over long distances, up to 1000 meters from the sampling point. This was done without causing any significant deformation or dilution of the initial gaseous signal, even for low amplitude leaks.

These results allow us to envisage the implementation of a relatively simple system for detecting and monitoring gas leaks through intermediate cap rock strata. This system will largely comprise conventional industrial gas sensors which are available off the shelf.

The direct measurement of gas flows emanating from the ground is one of the most effective ways to monitor a storage site. The INERIS accumulation chamber method has been improved to measure low and very low $\mathrm{CO}_{2}$ flux rates. It can now be used to measure a wide range of $\mathrm{CO}_{2}$ flux rates, from very low emission levels of 0.05 to $0.2 \mathrm{~cm}^{3} \cdot \mathrm{min}^{-1} \cdot \mathrm{m}^{-2}$ up to extremely high flux rates of some $3000 \mathrm{~cm}^{3} \cdot \mathrm{min}^{-1} \cdot \mathrm{m}^{-2}$.

The accuracy and operational characteristics of chamber method have been checked and validated by tests performed in a laboratory and on a test rig, as well as through field measurements taken under real conditions at sites that naturally release $\mathrm{CO}_{2}$. These tests have shown that the method has reached full technical maturity and that it can be applied on a practical level to detect and monitor $\mathrm{CO}_{2}$ and methane emissions on the ground's surface.

The two methods which have been tested are now operational and ready for integration into the surveillance strategy applied at future $\mathrm{CO}_{2}$ storage sites. They can be used at every stage of a storage site's life: site reconnaissance, definition of the initial state, injection, post-injection phase, and residual monitoring after the site has been abandoned. 


\section{INTRODUCTION}

The developments and results presented are for a large part taken from the work undertaken as part of the $\mathrm{CO}_{2}$ GeoCarbon-Monitoring project. This project was carried out between December 2005 and June 2008 and brought together seven partner organizations: BRGM, Gaz de France, IFP, INERIS, INPL, Schlumberger and Total.

Its primary aim was to develop, evaluate and test the different geophysical and geochemical monitoring methods for future storage sites that could be located in this specific geological context (Fabriol et al., 2007). This work was partly funded by the French National Research Agency (ANR).

The study's general objectives were:

- to respond to the technical and scientific aspects of installation inspection and safety;

- to provide practical solutions so as to set out a $\mathrm{CO}_{2}$ mass balance, i.e. the ratio between the $\mathrm{CO}_{2}$ effectively stored and that which is likely to be returned to the atmosphere through leaks.

A significant part of the work undertaken by INERIS covered gaseous phase geochemical monitoring methods on the surface and in the intermediate overburden strata at geological $\mathrm{CO}_{2}$ storage sites.

Perfecting and formalizing approaches to the geochemical monitoring of gasses is essential to evaluate the operational efficiency and integrity of future storage sites. This is because these methods must ensure a reliable characterization of the site's initial condition and, subsequently, the efficient detection of any $\mathrm{CO}_{2}$ leaks towards the surface.

After highlighting any leaks, the monitoring methods must also ensure an evaluation of the leaks' amplitude and extent in space. These data are essential for deciding on and undertaking repair and protective actions which are appropriate to the situation.

The work undertaken targeted two specific approaches which are essential when it comes to the monitoring of future storage sites:

- early detection (pre-alert), using analyses of gas samples taken from the base of the inspection boreholes that open into the intermediate cap rock strata;

- the detection and quantification of the gaseous flux of $\mathrm{CO}_{2}$ released from the ground into the atmosphere.

These two approaches were developed in the laboratory and then applied and tested under in-situ conditions which are as close as possible to those of future storage sites.

\section{LEAK DETECTION THROUGH THE SAMPLING AND ANALYSIS OF GAS FROM THE INTERMEDIATE CAP ROCK STRATA}

This work aimed to develop the technical equipment required to ensure reliable and durable instrumentation of inspection boreholes that are not drowned out and at a depth of a few tens to many hundreds of meters, or even deeper.

This instrumentation is intended to take samples and continuously analyze the main gaseous components, especially $\mathrm{CO}_{2}$, in the intermediate cap rock strata of the storage sites.

The aim is to have the technical resources necessary to monitor the gaseous make-up in these cap rock layers at a sufficient depth and with sufficient sensitivity so as to warn the operator of the presence of a gas leak without having to wait for it to appear on the surface. Where applicable, the prealert generated in this way may gives the operator more time to prepare and implement suitable corrective or protective actions.

\subsection{System Design and Laboratory Tests}

The experience gained by INERIS as part of the gaseous measurements taken in active and abandoned mines made it possible to favor the option of taking gaseous samples at the base of the borehole with a continuously running pump and a gaseous analysis performed on the surface using a specific measurement station (Besnard and Pokryszka, 2005).

This option presents several advantages:

- it is hardly affected by the diameter and size of the borehole;

- it avoids the difficulties encountered when installing gas sensors in the very restrictive space available within a borehole's casing;

- the exposure of the sensors, the most vulnerable part of the system, to the often aggressive conditions prevalent underground is greatly reduced;

- calibration, maintenance and modifications of the instrumentation and measurement are made easier.

A layout diagram for the solution retained for the remainder of this work is presented in Figure 1.

First of all, a prototype was designed and tested under laboratory conditions. This development work started with a review of industrial $\mathrm{CO}_{2}$ sensors available off the shelf. The preliminary trials performed made it possible to identify and then retain two construction approaches based on IR detection, which appeared to suit the requirements best. These comprised:

- a specific analyzer with a very low detection threshold of around $1 \mathrm{ppm}$, but with a measurement range limited to $2 \%$. Hereinafter called Sensor 1, and;

- an industrial sensor with an average theoretical resolution of $0.01 \%$ (100 ppm) but offering a very wide measurement range (0 to 20\%). Hereinafter called Sensor 2.

In the meantime, a sampling system based on the use of flexible tubes and on a membrane pump was designed and tested. This system, which was destined for the experimental phase, is relatively simple. Nevertheless, it allows operations 


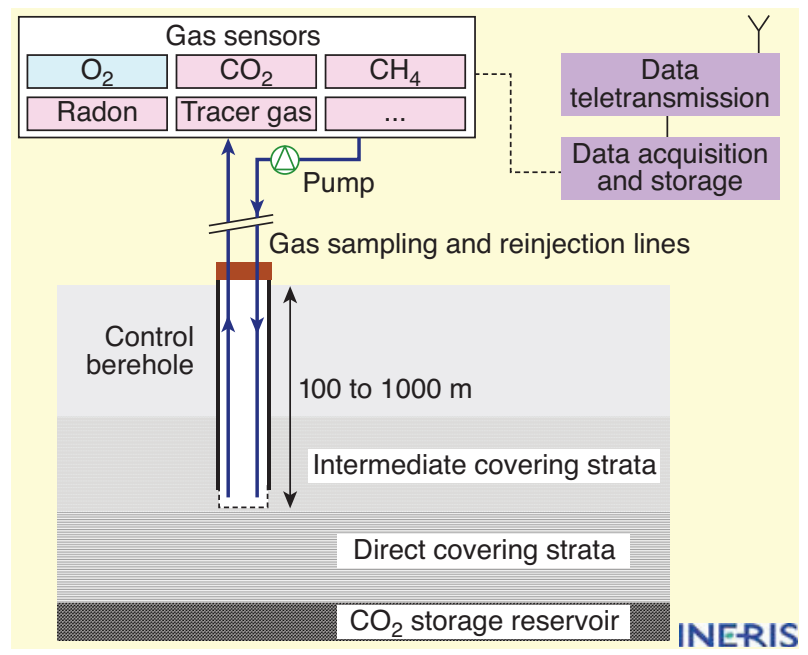

Figure 1

Principle of gas sampling and analysis from the bottom of the control boreholes for the early detection of $\mathrm{CO}_{2}$ leaks.

at significant depths, namely, 200 meters or more. Tests run under laboratory conditions showed that the gaseous sample can be taken over many hundreds of meters with enough of a gas flow rate to supply a conventional set of gas sensors $\left(\mathrm{O}_{2}\right.$, $\mathrm{CO}_{2}$, gaseous hydrocarbons, etc.).

Following the tests performed in the laboratory, there was a need to verify that the complete instrumentation worked under in-situ conditions.

\subsection{In-situ Tests of Leak Simulation and Detection}

The operational capacity of the system was checked under in-situ conditions at an experimental site belonging to GISOS (Groupement d'Intérêt Scientifique sur l'Impact et la Sécurité des Ouvrages Souterrains - Scientific Interest Group on the Impact and Safety of Underground Works) located above a salt mine using a solution mining process from the surface.

At this site, a deep borehole was available for instrumentation purposes. It was dry and opened into a layer of salt located at a depth of some 200 meters. The instrumentation implemented is used to continuously measure the characteristics of the atmosphere at the base of the borehole. It comprises a line to take gas samples from the bottom of the borehole and a line to reinject any gas removed back into the borehole, if required, as well as a gas analysis station that can accept the tested sensors along with a system for acquiring and storing the data measured (Fig. 2). The sensors implemented were those retained for the $\mathrm{CO}_{2}$ measurements during the laboratory test phase and an oxygen sensor which was used to check general atmospheric change inside the borehole.

Simulations of situations that may arise while monitoring future $\mathrm{CO}_{2}$ storage sites were performed twice in 2006 and 2007. They comprised an artificial simulation, through a controlled injection of $\mathrm{CO}_{2}$ into the borehole's atmosphere, of a gas leak which escaped through the covering layers and towards the borehole space. In successive tests, injections of $\mathrm{CO}_{2}$ were made at the bottom of the borehole at different distances from the sampling point and with variable gas flow rates $\left(0.01\right.$ to $\left.1000 \mathrm{~cm}^{3} / \mathrm{min}\right)$ and $\mathrm{CO}_{2}$ concentration levels (900 ppm to $100 \%)$.

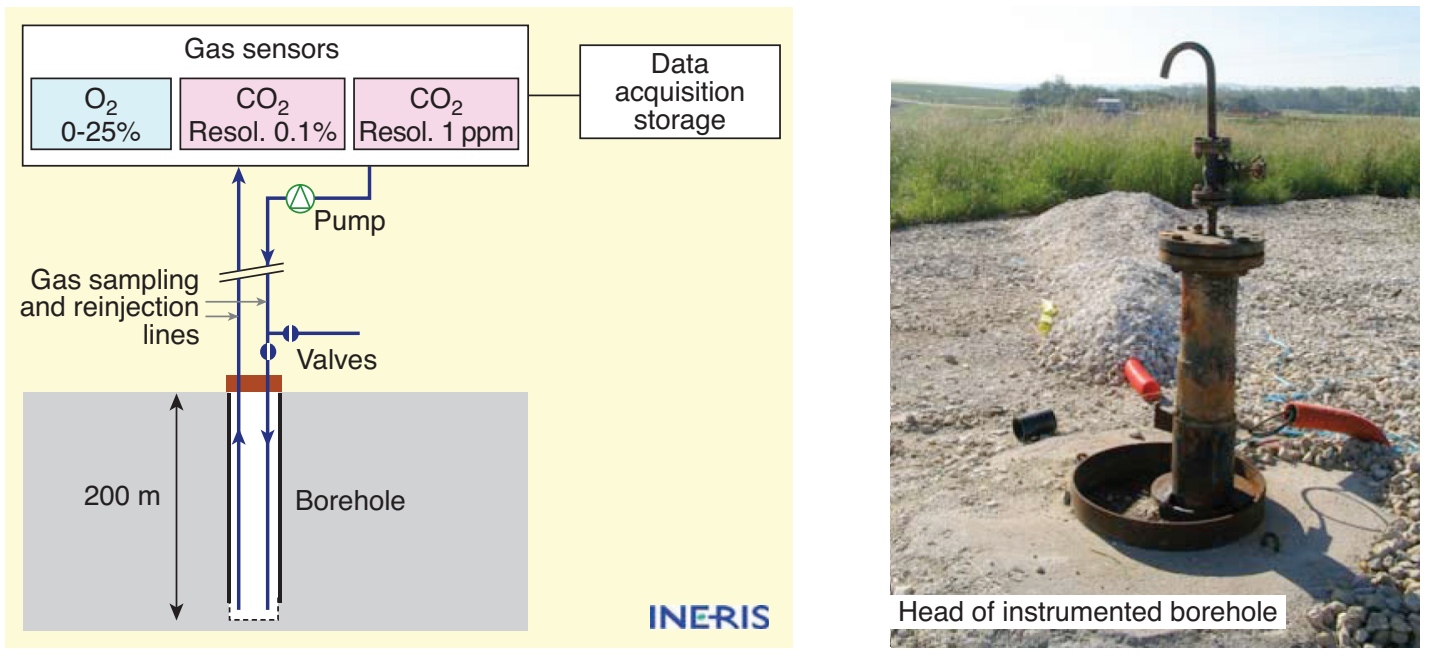

Figure 2

Instrumentation implemented for tests to simulate and detect $\mathrm{CO}_{2}$ leaks through the intermediate covering strata. 


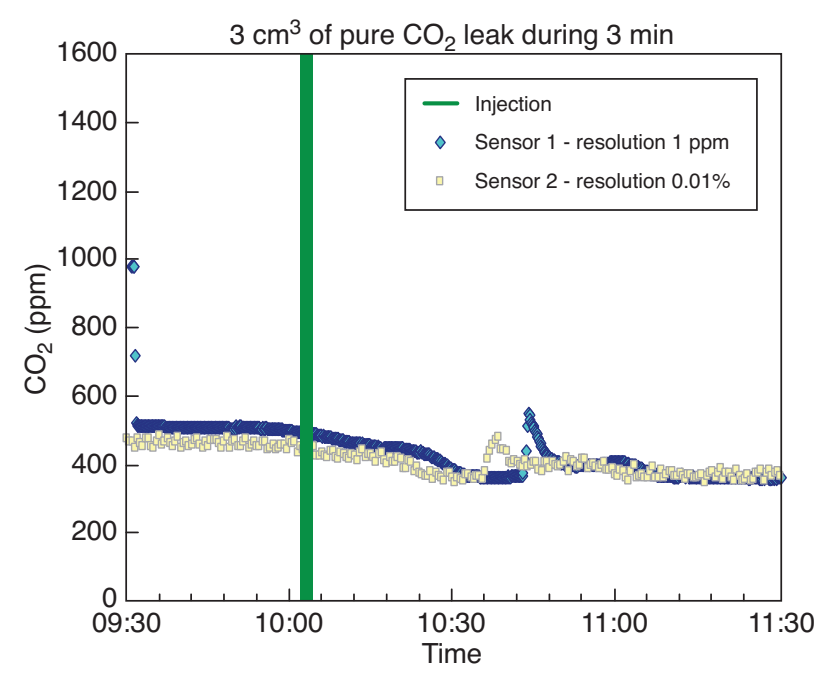

Figure 3

Example of the simulation and detection of a weak $\mathrm{CO}_{2}$ leak in a deep borehole.

The purpose of the sampling and measuring instrumentation implemented was to detect and to monitor the diffusion of this "leak" into the borehole's atmosphere. The tests confirmed that the installation implemented was able to detect and measure gas leaks arriving at a deep monitoring well with highly variable emission durations and flux rates. The two $\mathrm{CO}_{2}$ sensors tested worked very well in-situ and proved their usefulness:

- significant leaks ( $\left.>10 \mathrm{~cm}^{3} / \mathrm{min}\right)$ with high $\mathrm{CO}_{2}$ concentrations could be detected effectively by both sensors, but caused a fairly rapid saturation of the most sensitive sensor (Sensor 1). It was Sensor 2, the least accurate one, but the one with the widest measurement range that then took over to monitor the leak's development;

- low level leaks $\left(<10 \mathrm{~cm}^{3} / \mathrm{min}\right)$, which lasted a very short time or which were characterized by low concentration levels were of course better detected and monitored by Sensor 1.

By doubling up the $\mathrm{CO}_{2}$ measurements, with different detection thresholds and measurement ranges, it has therefore become possible to better detect and monitor the various leakage cases that might occur.

We should note that it was possible to detect extremely low emissions in the range of less than $0.1 \mathrm{~cm}^{3} / \mathrm{min}$.

As an example, Figure 3 shows the system's response to a very small $\mathrm{CO}_{2}$ leak of $1 \mathrm{~cm}^{3} / \mathrm{min}$ over three minutes (a total injected volume of $\mathrm{CO}_{2}$ of $3 \mathrm{~cm}^{3}$ ).

\subsection{Long Distance Gas Sampling Test}

Laboratory tests have shown that the sampling system - as it stands - made it possible to perform gas transfers, with a sufficient flow rate level, over a distance of a few hundred meters. This system's correct operation was confirmed in the in-situ experiments undertaken in a vertical $200 \mathrm{~m}$ deep well.

One of the questions identified during this phase was the feasibility (and the practical conditions) of taking samples at far greater distances (depths) of around 1000 meters, i.e. at depths that are closer to those of the direct cap rock layers at future storage sites.

Aside from the problem of far greater aeraulic resistance on the sampling lines, which would require the pumping systems to be adapted, the transit of gas over long distances can also lead to changes in the gas composition itself due to the dilution and homogenization of the gaseous mixture along the route from the sampling point right up to the analysis station.

A preliminary signal of a $\mathrm{CO}_{2}$ leak (puff of gas) at the bottom of a monitoring borehole could in this case be progressively spread out and diluted until it becomes undetectable once it has fallen below the sensor detection limit (Fig. 4). The main elements that influence the transit of the gas are in this case the diameter and the roughness of the sampling lines, the transit rate (linked to the cross-section of the sampling line and the pump flow rate) as well as the initial characteristics of the gaseous signals, characterized in particular by the gas concentration level and the duration of the signal.

On the basis of a simplified analytical approach taken to calculate gas sampling parameters (required flow-rate, low velocity, pressure, etc.), it was possible to approximately evaluate the characteristics of the equipment needed to carry out a correct gas transit operation (especially based on the aeraulic characteristics of the pump and the sampling line). The fastest and most direct way to verify the analytical simulations was to perform specific tests in-situ.

As no very deep vertical borehole was available, an opportunity arose to apply the principles of long distance gaseous sampling in a closed mine in the Lorraine iron ore basin under almost real-life conditions as part of a study undertaken by INERIS on behalf of the French Ministry of Industry and Finance. The purpose of the study was to monitor mine voids with an atmosphere that may become poor in oxygen and rich in $\mathrm{CO}_{2}$ following a certain number of geochemical reactions that are triggered or amplified by site flooding.

A long distance gaseous sampling system was set up in a disused mine gallery (the Algrange gallery). It was used to take samples and perform gaseous transfers from the mine voids to the surface, over distances of up to 1000 meters. A gas analysis and data acquisition station was provided at the head of the sampling line. A series of specific experiments were undertaken at this site in 2007 which aimed at studying gas transit times and possible changes in the gaseous 


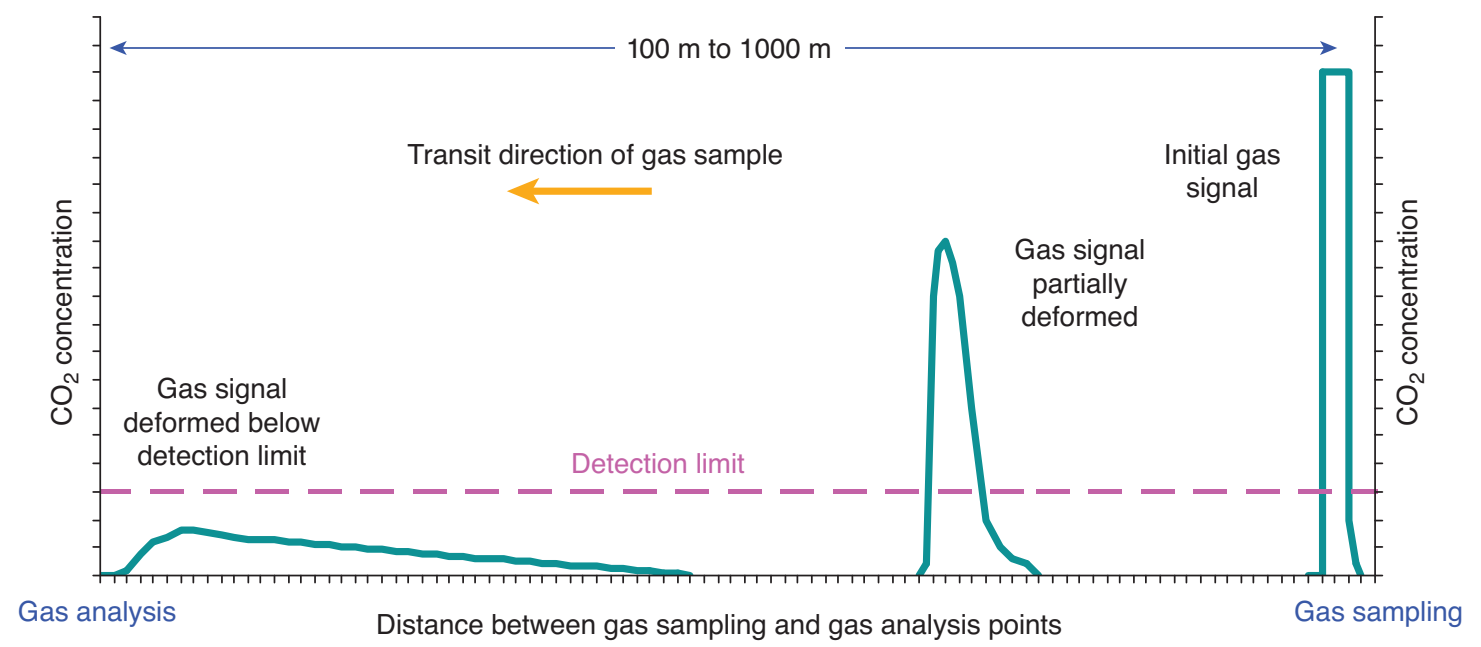

Figure 4

Possible attenuation of the gas concentration level during sampling and after long distance transit.

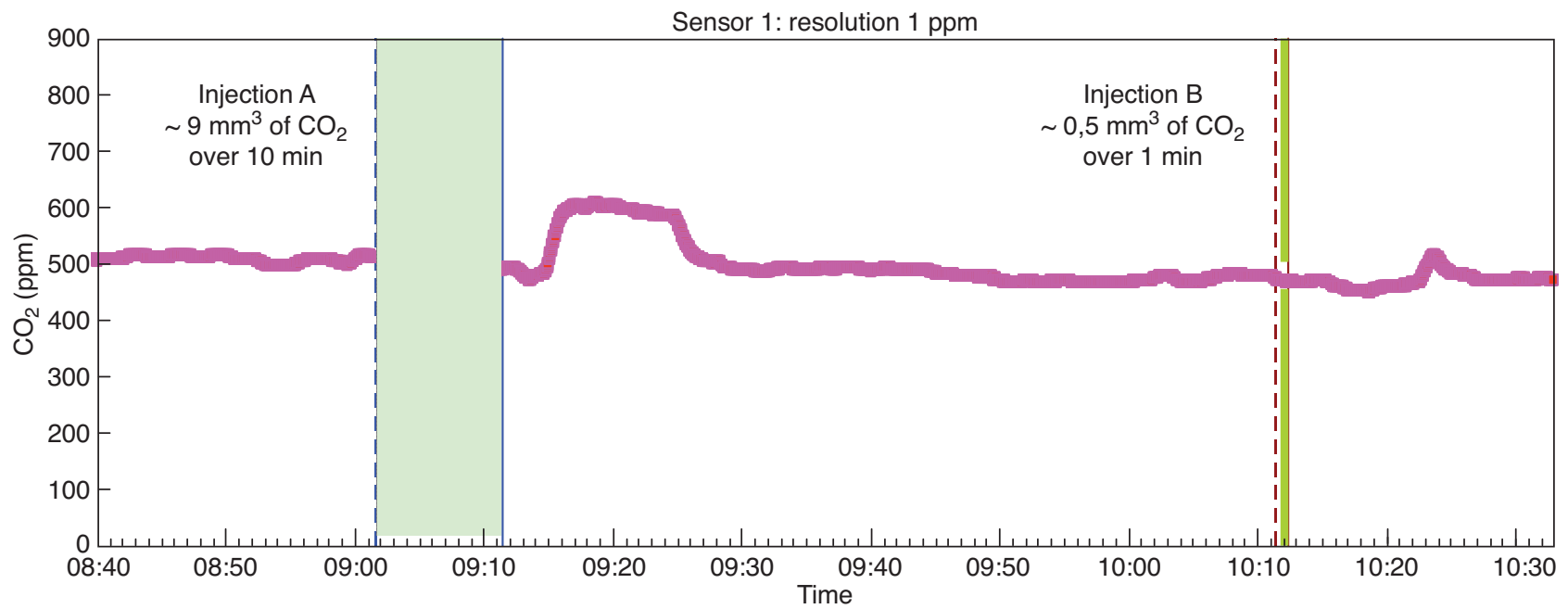

Figure 5

Long distance sampling tests. Example of the transit and detection of an extremely weak $\mathrm{CO}_{2}$ leak.

composition over long-distance transfers. The experiments comprised an artificial simulation of slight leaks of $\mathrm{CO}_{2}$ through a controlled injection of this gas $\left(0.001\right.$ to $\left.10 \mathrm{~cm}^{3} / \mathrm{min}\right)$ into the atmosphere at the end of the sampling line. The characteristics of the gas were then observed when it arrived at the analysis station via the sampling line. Just like for the deep well trial, two different sensors were tested (with resolutions of $0.01 \%$ and $1 \mathrm{ppm}$ ).

These tests have shown that it is possible to achieve a transfer over a distance of 1000 meters with enough of a flow rate to supply a conventional set of gaseous sensors
$\left(\mathrm{O}_{2}, \mathrm{CO}_{2}\right.$, gaseous hydrocarbons, etc. $)$. At the same time, the transit of a puff (leak) of $\mathrm{CO}_{2}$ via the sampling and analysis circuit may take place with a relatively short response time (15 to $20 \mathrm{~min}$ ) without incurring any excessive dilution of gas.

It was also possible to perform a transfer and an analysis of mixtures with a very low $\mathrm{CO}_{2}$ content $(<1000 \mathrm{ppm})$. Figure 5 shows an example of the transit and detection of two extremely small single $\mathrm{CO}_{2}$ leaks with a flow rate of less than $1 \mathrm{~mm}^{3} / \mathrm{min}$ and a total volume of released gas of less than $10 \mathrm{~mm}^{3}$. 


\subsection{Conclusions Relating to Method Development and Testing}

The system developed and the in-situ experiments performed by coming as close as possible to real-life conditions, have shown that the detection of $\mathrm{CO}_{2}$ leaks that cross through the intermediate overburden rock strata can be performed by taking and analyzing a sample of gas accumulated in deep monitoring boreholes. Good results were especially obtained when detecting small puffs of gas arriving at the base of the well, which can serve as a precursor to a more serious leak.

In the same way, the transit of gas over a long distance was possible up to 1000 meters from the sampling point; in addition, this did not cause any major dilution of the gaseous signal, even for very slight amplitude leaks $\left(\mathrm{CO}_{2}\right.$ volume of less than $10 \mathrm{~mm}^{3}$ ).

These results make it possible to envisage a system for detecting and monitoring leaks through the intermediate covering strata that is relatively simple and based, for a large part, on conventional industrial gas sensors.

\section{DETECTING AND QUANTIFYING THE $\mathrm{CO}_{2}$ GASEOUS FLUX FROM GROUND TO ATMOSPHERE}

Directly measuring the gaseous flux coming out of the ground is one of the most efficient ways to check and monitor a storage site. Nevertheless, this approach poses a complex problem from a technical and a measurement quality perspective. One of the major difficulties resides in having a measurement device that is both hardly invasive, simple and easy to use in-situ while also complying with measurement quality demands in terms of sensitivity and reliability.

INERIS has worked for more than 20 years on problems linked to gaseous emissions and has designed and perfected an operational method that makes it possible to measure the gaseous flux at the ground's surface. The initial study results demonstrated an excellent aptitude of the chamber's method for detecting and measuring gas fluxes in different contexts. Consequently, it was decided that the accumulation chamber method should be developed. This approach has also been developed and implemented by various research centers (Denmead, 1979; Jury et al., 1982; Christensen, 1983; Mosier, 1990; Reinhart, 1992).

The option chosen and developed by INERIS was the accumulation chamber coupled with an external recirculation circuit for the analysis of gas. The procedures involved in this method are protected by a French patent (No. 96-05996, filed on May 14th 1996) and a European invention patent (No. EP0807822B1) under the heading "Measurement of gas flows through surfaces".

In practice, this method has been used for over 15 years for landfills, polluted soils and closed mines to measure the flux of gaseous hydrocarbons (Pokryszka and Tauziède,
2000) and VOC emissions (Rouil et al., 2000). This method can be very useful in the context of geological $\mathrm{CO}_{2}$ storage as it allows local and very quick measurements of the gas flux across the ground's surface to be taken.

Nevertheless, due to an insufficient analytical resolution and a lack of reliability in the measurement capacity of the mobile or portable measurement equipment available until now, the method has not been fully operational for in-situ measurements of weak fluxes of carbon dioxide. The adaptation of the INERIS accumulation chamber in order to make it able to detect and quantify low gaseous flux of $\mathrm{CO}_{2}$ was achieved by integrating a high resolution portable analyzer into the system.

\subsection{Principles of Prior Measurements and Developments}

The approach perfected by INERIS, and called the "accumulation chamber with external recirculation method" can be classified as an intermediate technique, between a static and a dynamic principle.

The method comprises using an enclosure (chamber) to cover a certain ground surface area $\left(0.25 \mathrm{~m}^{2}\right)$ in a practically sealed manner, without significantly modifying the gas migration conditions. This operation creates an "accumulation" effect that forms the basic phenomena for performing a measurement of the local gas flux.

This is because the gas released by the covered surface accumulates in the confined atmosphere inside the chamber that is initially made up of air and that is practically free of, or hardly laden with, the gas to be measured.

We then note a progressive rise in the average gas content inside the chamber. Initially, this rise is almost proportional to the accumulation time and can be taken to be a linear function of gas concentration as a function of time.

In the INERIS method, it is this part of the phenomena that is observed and used so as to deduce the local gas flux. To do this, a system makes it possible to continuously sample a certain quantity of the gaseous mixture from inside the chamber. The gas sample is carried by a pipe to an analyzer and then re-injected into the chamber, thereby creating gas recirculation. Tracking the rate at which the re-circulated mixture becomes enriched makes it possible to deduce the local gas flux at the point concerned.

A layout diagram for the method is presented in Figure 6.

So as to be able to take a correct measurement, the accumulation phenomena must be achieved over a sufficient length of time together with a suitable degree of quality and regularity. These characteristics are dependent on a number of elements, the main ones being: the intensity of the gaseous flow, the chamber volume and its geometry, chamber sealing and its contact with the ground, the way the gas that has accumulated within the chamber is distributed and the characteristics of the system to analyze the gas. 


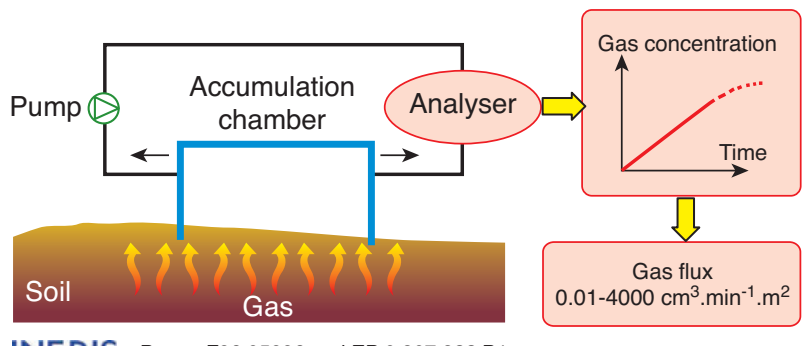

INERIS Patent F96 05996 and EP 0807822 B1

Figure 6

INERIS accumulation and external recirculation chamber. Method principle.

All of these elements were studied and optimized during the design and validation phases applied to the method on a test rig. The validation tests also revealed that the variations between the fluxes as they are measured and the ones actually released may be very significant. This is because the gaseous exchanges at the ground-air interface are most often low intensity phenomena that are very fragile and very easy to upset (Mosier, 1990).

Many comparative tests between fluxes released and fluxes measured were carried out by examining a number of configurations. In particular, different gas flows and ground with differing permeability characteristics have made it possible to determine corrective factors so as to offset any interference caused between the measurement device and the gaseous flow to be measured.

It should also be noted that the measuring accuracy of the method was verified and confirmed (in the case of methane) as part of a program to compare the different methods, undertaken under the leadership of the French Environment and Energy Management Agency (ADEME) on a test rig and in-situ (Savanne et al., 1997).

In parallel with the development during the 1990s of methane flux measurements, a certain number of tests were performed to adapt the method to the $\mathrm{CO}_{2}$ flux. Nevertheless, they did not achieve an operational solution. The main obstacle was the difficulty in finding an analyzer that was reliable, compact, transportable in the field and that also provided the required measurement qualities. It must be compatible with both the chamber's operating principles and present a resolution and dynamic response range that is good enough to respond correctly in the presence of a significant background of atmospheric $\mathrm{CO}_{2}$ (some $400 \mathrm{ppm}$ or even a lot more at sites that produce high emission levels).

A more in-depth study was conducted between 2002 and 2004 as part of a program that was paid for by INERIS out of its own funds. In fine, this study made it possible to develop a direct and operational measurement of the $\mathrm{CO}_{2}$ flux at the ground's surface. Then, after trying various analyzers which were available off the shelf, two partially satisfactory technical solutions were found, based on IR detection:

- a Unor 710 analyzer characterized by high resolution $(1 \mathrm{ppm})$, high precision and a wide measurement range, but which is also hard to use in-situ, and;

- another device, the Dräger Multiwarn, which is very compact and portable but which provides a smaller resolution (some $100 \mathrm{ppm}$ ). Consequently, it does not measure a weak flux of less than $5 \mathrm{~cm}^{3} \cdot \mathrm{min}^{-1} \cdot \mathrm{m}^{-2}$ and nor does it provide a sufficient degree of accuracy for average flux levels.

Despite these drawbacks and limits, $\mathrm{CO}_{2}$ flux measurements have become possible. The method calibrations performed in the laboratory revealed a fairly good correlation between the flux actually released and the flux deduced from the measurements.

In parallel, a series of field tests made it possible to check the proper operation of the new set-ups when applied in practice. The measurements were made in the context of $\mathrm{CO}_{2}$ emissions of a mining or biogenic origin on the ground's surface. Overall, these tests gave good results but they also confirmed the technical weaknesses mentioned previously which affected the two technical solutions developed. Consequently, specific work has been undertaken with the general aim of developing a fully portable device that ensures a good degree of measurement accuracy and resolution.

\subsection{Testing and Validating the Method with a New Sensor for Measuring Low $\mathrm{CO}_{2}$ Flux}

An improvement to the method and a new set-up to detect and quantify low gaseous $\mathrm{CO}_{2}$ flux rates were made between 2004 and 2007. This became possible thanks to a notable technological advance which was achieved over the past few years in the development of high resolution $\mathrm{CO}_{2}$ sensors that are highly compact.

After a number of tests were carried out, the analyzer that was chosen and integrated into the measurement system was a Licor 820 based on IR detection. It provides a resolution of $1 \mathrm{ppm}$ with a scale range of up to $2000 \mathrm{ppm}$ or $20000 \mathrm{ppm}$ depending on the (interchangeable) sensor chosen. Thanks to its very limited size, it was possible to install the analyzer on the chamber itself. The complete assembly forms a device that can be carried by the operator and that is easy to use in the field (refer to the photograph in Fig. 7).

Measurement accuracy tests were performed on a test rig used to simulate a controlled $\mathrm{CO}_{2}$ flux which emanated from the ground. At this stage it was also possible to determine the influence of environmental parameters such as the nature of the soil, soil humidity, the wind, etc. on the measurement results. A schematic diagram of the test rig used is presented in Figure 8. The details of this rig and the principles of the test performed are presented in an earlier publication (Savanne et al., 1997). 

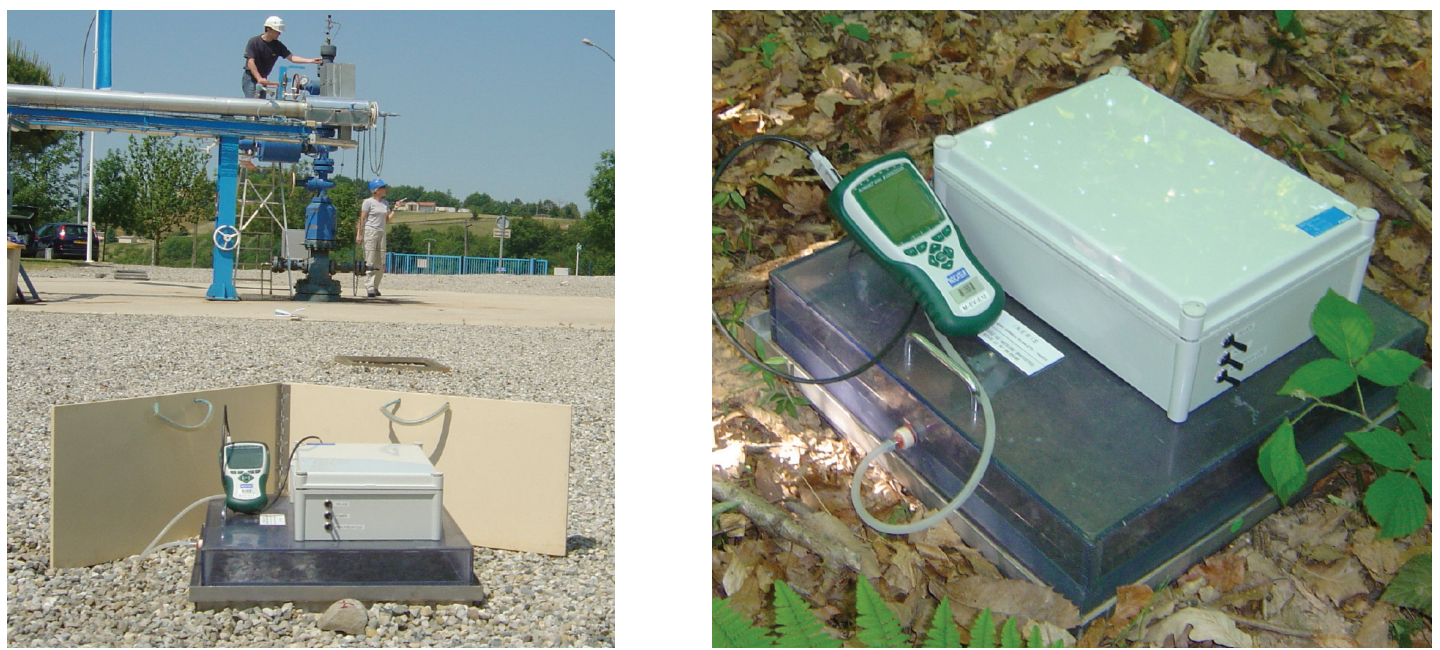

Figure 7

Device for $\mathrm{CO}_{2}$ flux measurements at the ground/atmosphere interface.

These tests showed that the modified system worked very well and that it had the ability to perform the measurements across a wide range of $\mathrm{CO}_{2}$ flux rates, from extremely strong emission levels of around $3000 \mathrm{~cm}^{3} \cdot \mathrm{min}^{-1} \cdot \mathrm{m}^{-2}$ down to very low flux rates.

The lower threshold for a measurement that is still valid from a measuring quality perspective is indeed a very low one of 0.05 to $0.2 \mathrm{~cm}^{3} \cdot \mathrm{min}^{-1} \cdot \mathrm{m}^{-2}$, i.e. a value that is far below the usual level of emissions of a biogenic origin as observed under European or similar climatic conditions (Raich and Schlesinger, 1992; von Arnold et al., 2005). The new system also permits the detection of a flux (or a change in flux) that is even weaker, of some $0.01 \mathrm{~cm}^{3} \cdot \mathrm{min}^{-1} \cdot \mathrm{m}^{-2}$, with, however, a greater degree of uncertainty.

These tests also showed a very good degree of general linearity in the "measured flux-real flux" response throughout the entire measurement domain ensured by the new device, making its use possible in cases of highly heterogeneous emissions (refer to Fig. 9).

The deviations between the real $\mathrm{CO}_{2}$ flux and measured flux levels established on the test rig, regarding the emission level most often encountered in the field ( 0 to $\left.400 \mathrm{~cm}^{3} \cdot \mathrm{min}^{-1} \cdot \mathrm{m}^{-2}\right)$, are presented in Figure 10. They are established from 13 different series of measurements taken for the various flux levels using a number of measurements per series. We observed that overall these deviations are small as their average values for the different series do not exceed $\pm 5 \%$. For flux levels of less than $150 \mathrm{~cm}^{3} \cdot \mathrm{min}^{-1} \cdot \mathrm{m}^{-2}$, these deviations are randomly spread and remain fairly symmetrical around a nil deviation, which indicates that the measuring system does not present any tendency to under- or overestimate the measured values.

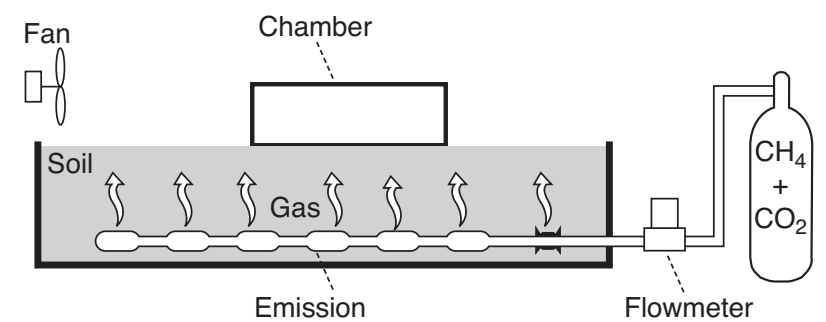

Figure 8

Test rig used for the validation of the device for measuring soil-surface gas flux (simplified diagram).

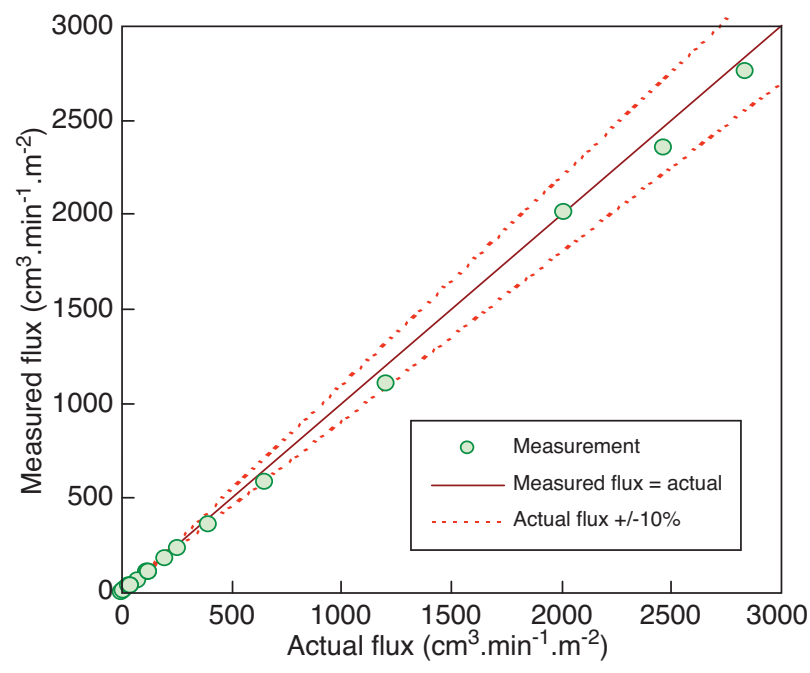

Figure 9

Validation of the new development for measuring the flux of $\mathrm{CO}_{2}$ on a test rig. Comparison of the actual flux released and the flux measured. 


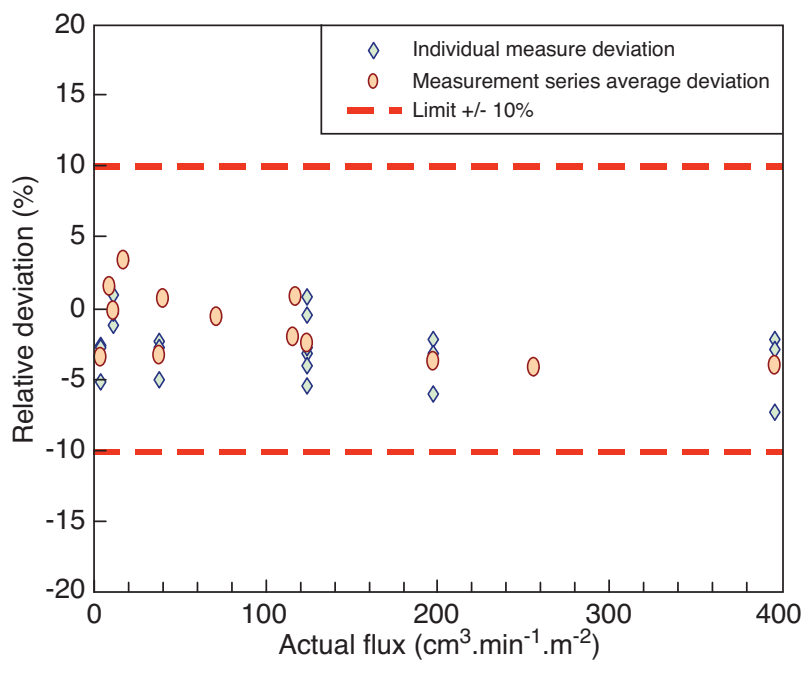

Figure 10

Deviations and the repeatability of measurements observed on the test rig.

A slight systematic underestimation of the measurement that does not exceed a few percent has been observed for $200 \mathrm{~cm}^{3} \cdot \mathrm{min}^{-1} \cdot \mathrm{m}^{-2}$ or higher flux rates.

We also noted that the dispersion of individual measurements around the value for each series is limited and does not exceed $7 \%$ of the flux level which is truly released. This shows a good degree of repeatability in the measurements and one that is quite sufficient under the conditions of real storage sites.

All of these tests were carried out in a calm atmosphere without any significant air movement (wind). The influence of the wind on the measurements taken was studied during the method's design phase and when it was being validated for the measurement of methane flux levels (Savanne et al., 1997). For wind levels that do not exceed $4.5 \mathrm{~m} . \mathrm{s}^{-1}$, this influence translates into a greater dispersion in measurements, but one that is perfectly acceptable in practice. This is because the relative complementary deviations due to the wind were at most $8 \%$.

The wind's influence is linked to the general operating principles of an accumulation chamber and is only very slightly dependent on the type of gas measured. The integration of the new $\mathrm{CO}_{2}$ analyzer into the mechanism has no bearing on the construction and the operating mode of the chamber itself. The tests carried out previously can therefore, on the whole, be transposed to measure the $\mathrm{CO}_{2}$ flux.

This aspect may once again be verified in detail by specific tests carried out when future refinements or modifications are made to the method. Nevertheless, the tests conducted to measure the flux of $\mathrm{CO}_{2}$ in-situ have already shown that the method behaves normally in the presence of moderate winds (refer to Sect. 2.3).
To sum up, the validation phase conducted in the laboratory yielded very good results and allowed us to move to the next step, one that comprises testing and validating the method in-situ.

\subsection{Testing and Validation of the Method Under In-situ Conditions}

After the development phase in the laboratory, the method's operational characteristics were tested in the field on sites that naturally release $\mathrm{CO}_{2}$ : the sites of Montmiral and Sainte Marguerite. Many hundreds of flux measurements were taken as part of the four research campaigns undertaken in 2006 and in 2007 with the other partners in the GeoCarbon Monitoring project.

These in-situ investigations have confirmed the method's operational qualities, namely, its robustness and ease of use.

In the same way, from a $\mathrm{CO}_{2}$ flow characterization perspective, the method's implementation at natural $\mathrm{CO}_{2}$ emission sites has shown that the methodology used would make it possible to differentiate between emissions which are spread out both homogeneously and diffusely in space (Montmiral site) and highly heterogeneous and more localized emissions which are observed at the Sainte-Marguerite site (refer to sect. 2.5).

It was indeed possible to observe that the method functioned correctly over the entire measurement scale range, from very low flux levels $\left(<0.5 \mathrm{~cm}^{3} \cdot \mathrm{min}^{-1} \cdot \mathrm{m}^{-2}\right)$ to medium ones at the Montmiral site, to extremely high emission levels (with a flux close to $3000 \mathrm{~cm}^{3} \cdot \mathrm{min}^{-1} \cdot \mathrm{m}^{-2}$ ) as observed locally at the Sainte Marguerite nature site (Charmoille et al., 2008).

The measurements that were reproduced a number of times at the same locations made it possible to assess in parallel the repeatability of the method under real-life conditions as encountered in-situ. An example of the repeated measurements is shown in Figure 11.

A summary of the results obtained during the various repeatability tests conducted at the two sites studied is presented in Figure 12. This relates to the range of fluxes most often observed in practice, 0 to $50 \mathrm{~cm}^{3} \cdot \mathrm{min}^{-1} \cdot \mathrm{m}^{-2}$. It is possible to observe that, regardless of the flux level measured, the relative deviations in the one-off measurements in relation to the average series values are fairly limited and do not exceed $11 \%$. In the same way, the standard deviations in the various measurement series are relatively low, for they are less than $8 \%$ of the average series value.

It should be noted that in addition to the inherent characteristics of the measurement method, the degree of dispersion as determined in this way for the results also includes a certain number of "external" factors. This especially involves the influence of in-situ meteorological conditions (the presence of low to medium wind levels during the measurements) and the possible variability in the actual 


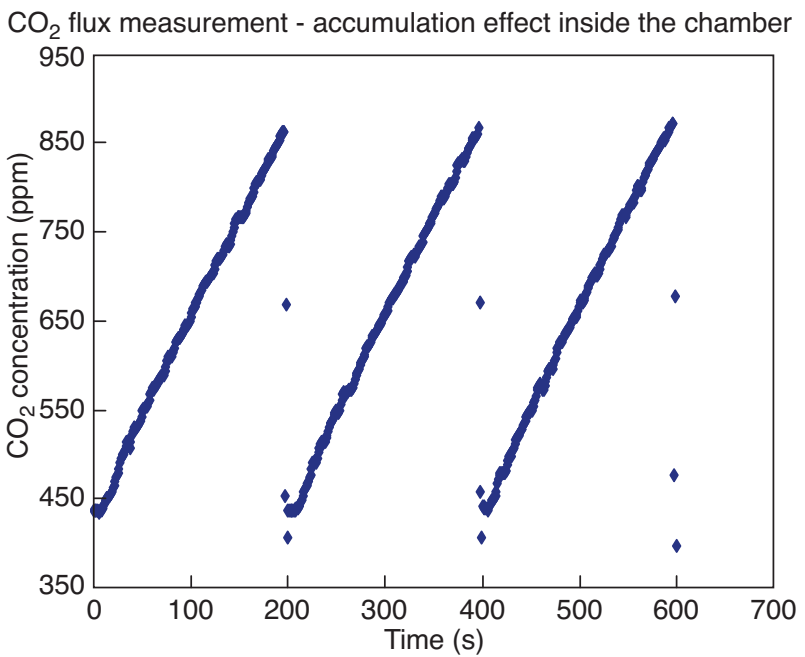

Figure 11

Example of in-situ $\mathrm{CO}_{2}$ flux measurements repeated at the same point.

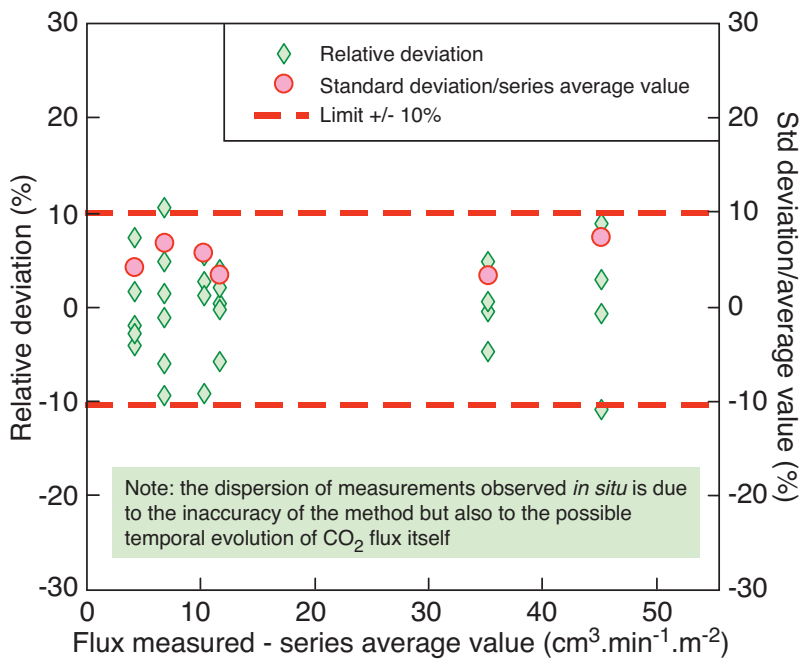

Figure 12

Deviations and repeatability in $\mathrm{CO}_{2}$ flux measurements as taken in-situ at the natural $\mathrm{CO}_{2}$ emission sites. gaseous emissions themselves. Consequently, dispersion in the in-situ measurements within a range that is limited to some $+10 \%$ of the average value constitutes, from a practical perspective, a good result which shows that the method's quality of measurement is sufficient to ensure adequate measurement reliability under in-situ conditions.

\subsection{Conclusions Relating to Method Development and Testing}

The developments and tests performed have made it possible to perfect the INERIS method for measuring the $\mathrm{CO}_{2}$ flux at the ground/air interface. A significant improvement was made to the measurement of very low flux levels by implementing a new high resolution sensor. Integrating this sensor has also made the measurement device a truly portable one and therefore facilitated its use in the field.

This makes it possible to carry out a significant number of measurements in geographically extensive areas in a limited period of time. For example, on normally accessible terrain, all of the flux measurement operations required at one point do not take more than 10 minutes.

The method can now be considered to be fully operational and validated from a measurement quality perspective. It is also available for measuring the flux of methane, the gas that is the most relevant in the case of $\mathrm{CO}_{2}$ storage in post hydrocarbon (gas or oil) reservoirs. Adaptations to the method in order to measure other gases may also be envisaged, especially for the gasses envisaged to trace the injected $\mathrm{CO}_{2}$.

\subsection{Example of Results Obtained at Natural $\mathrm{CO}_{2}$ Fields}

During the testing of the method at natural $\mathrm{CO}_{2}$ emission sites, a number of practical results were obtained under conditions that are close to those of future storage sites. Here we can show two sets of characteristic results that demonstrate the method's capacity to respond to the practical problems that may arise when managing the actual storage sites.

At the Montmiral site, a high pressure natural $\mathrm{CO}_{2}$ reservoir located at a depth of more than 2000 meters is exploited from the surface using a deep well. Prior measurements have revealed the presence of significant amounts of $\mathrm{CO}_{2}$ in the ground on the site's surface, something that may suggest a leak that is linked to the exploitation well.

The investigations undertaken by INERIS in 2006 confirmed the presence of $\mathrm{CO}_{2}$ emissions from underground. That said, repeated flux measurements made within a certain perimeter around the wellhead have shown that these emissions are more likely to be unrelated to the presence of the exploitation well (Fig. 13). This is because the gas emission levels are very weak around the wellhead, while their overall level increases when one moves away from the well by 10 to 150 meters.

At the volcanic site of Sainte-Marguerite in France's central mountain range, important measurements were undertaken in 2006 aimed at characterizing $\mathrm{CO}_{2}$ emissions from the ground over an area of some 5 hectares. The characteristics of the site studied are presented in another publication (Battani et $a l .$, 2009). The measurements were performed with a rectangular grid and with a regular-stratified repartition of measure 


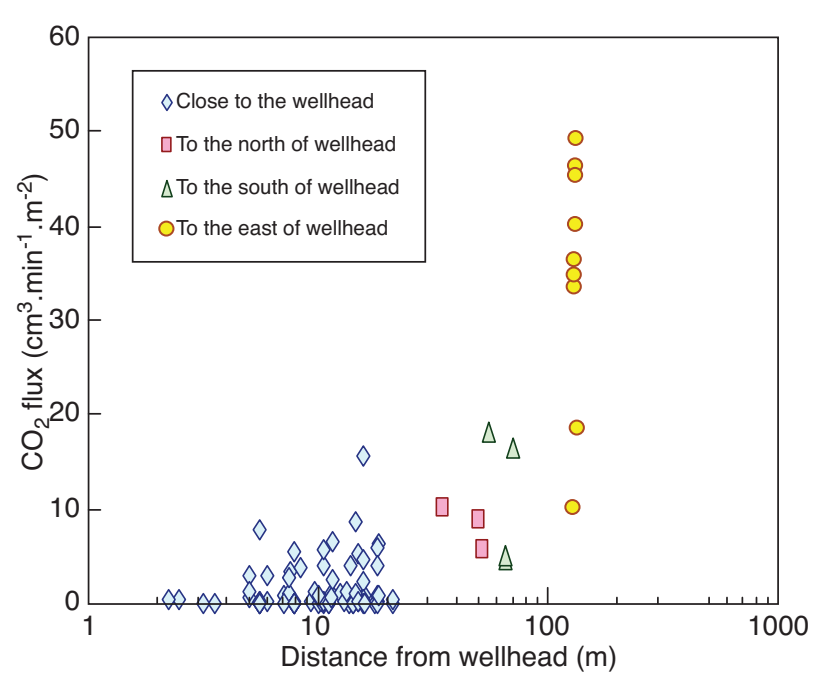

Figure 13

$\mathrm{CO}_{2}$ flux measured on the surface around the exploitation well at the Montmiral natural $\mathrm{CO}_{2}$ field.

points ( $\sim 30$ per hectare). Its showed that this site is highly emissive overall (with an overall $\mathrm{CO}_{2}$ flow rate of $1.6 \mathrm{~m}^{3} / \mathrm{min}$ ). Mapping the measured flux made it possible to highlight the highly heterogeneous nature of emissions with two especially emissive zones (Fig. 14a).

This very large number of measurements made the simulation of the various sampling options possible. Geostatistical processing has shown that the emission characteristics of the Sainte-Marguerite site enable a random 30\% reduction in the number of measurements that are actually taken. This can be done without any significant deterioration in the quality of the final results from the point of view of the spatial localization of the most highly emissive zones and in the quantification of the overall flow rate of $\mathrm{CO}_{2}$ emitted.

A $50 \%$ reduction in the number of measurements (some 15 measurements per hectare) still makes it possible to assess the overall distribution of $\mathrm{CO}_{2}$ emissions in space. The loss of information is however excessive, as some emission zones are no longer identified (Fig. 14b).

These results provide initial indications on the sampling strategy to measure the flux of $\mathrm{CO}_{2}$ on the site's surface. They also show that defining this strategy and adapting it to a given local site still requires a good deal of testing and optimization work.

\section{INTEGRATION OF THE METHODS DEVELOPED IN THE OF $\mathrm{CO}_{2}$ STORAGE SITE MONITORING STRATEGY AND FUTURE DEVELOPMENTS}

The two methods developed have the advantage of ensuring direct measurements and providing real-time data on the possible presence or, on the contrary, on the absence of any $\mathrm{CO}_{2}$ leaks. Their technical maturity is now such that it is possible to move forward to the step where they are integrated into the surveillance strategy for future storage sites.

They can indeed be used during the various phases in the life of a real $\mathrm{CO}_{2}$ storage site:

- by defining the site's initial state;
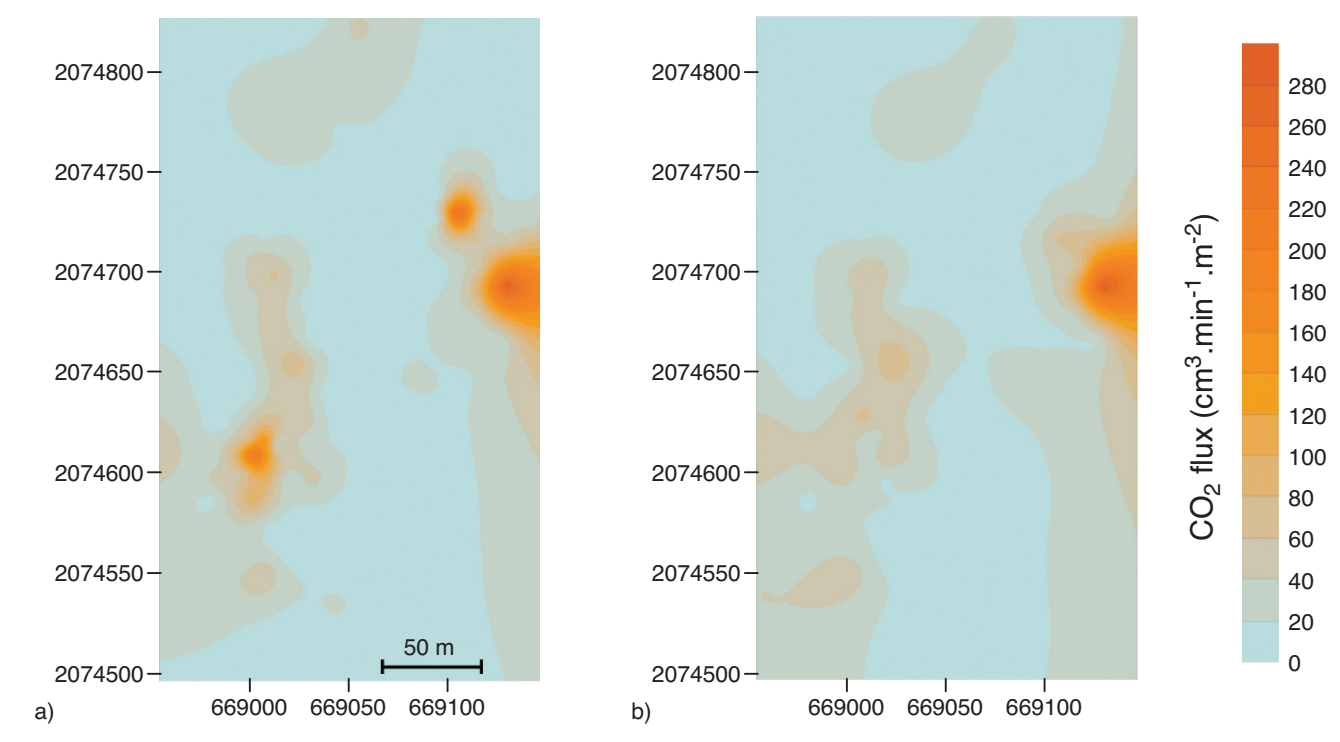

Figure 14

Map of the flux of $\mathrm{CO}_{2}$ from the Ste-Marguerite site in September 2006: a) Map compiled from all 150 measurements; b) Example of a map compiled from 70 randomly chosen measurements. 
- by monitoring gaseous emissions on the site's surface during and after injection;

- by detecting, locating and determining the importance of any possible leaks;

- by checking the efficiency of the curative means implemented to stop the leak;

- through long-term monitoring after the site has been abandoned.

A specific analysis is required when it comes to the practical conditions of this integration and a certain number of questions still need to be answered:

- for monitoring wells: How many boreholes are required and in what position in relation to the one or more $\mathrm{CO}_{2}$ injection points? What overburden geological strata depth should be aimed for?

- for surface gas flux measurements: How many measurement points are needed per unit of surface area to be monitored? How many measurement campaigns are required to define an initial site's state and its seasonal variability? Should the measurements be taken at fixed points to ensure monitoring over time or will random sampling suffice? What is the measurement frequency following the storage site's lifetime?

It is probable that not one single study of real-life cases will be able to answer these questions and that they will surely require a search for an optimum trade-off between the quality of the expected results and the cost of the measurements undertaken. There are some very interesting recent publications or research projects on this subject (Lewicki et al., 2005; Cortis et al., 2008). A very important piece of work has already been carried out in this domain, particularly in the field of natural emissions, agricultural emissions and emissions from landfill sites. Nevertheless, many questions remain in relation to the geochemical monitoring of large geographic areas of future $\mathrm{CO}_{2}$ storage sites.

Furthermore, at a point in the future, it would also be interesting to widen the analytical means to follow gasses envisaged to trace the injected $\mathrm{CO}_{2}$ and some endogenous gasses (methane, $\mathrm{H}_{2} \mathrm{~S}$, etc.) that are potentially dangerous and that may be mobilized by the $\mathrm{CO}_{2}$ injections .

\section{CONCLUSION}

The tests which have been undertaken and which sought to be as close as possible to the future storage site's conditions have shown that detecting $\mathrm{CO}_{2}$ leaks that cross through the intermediate overburden layers is possible by sampling and analyzing the gases which accumulate in the deep monitoring boreholes. The detection of small releases of gas which approached the base of the monitoring hole gave rise to a number of good results. These releases may be a precursor to a larger leak.
Likewise, long distance gas transits can be achieved up to 1000 meters away from the sampling point without causing any major deformation of or dilution to the gaseous signal, even for leaks of a very limited amplitude.

These results make it possible to envisage a relatively simple system for detecting and monitoring leaks through intermediate cap rock strata, one that is for a large part based on the use of conventional industrial $\mathrm{CO}_{2}$ sensors available off the shelf. A certain number of technical and methodological problems have yet to be resolved, especially:

- technical principles (construction, materials, etc.) for sampling lines that need to last for long periods of time (ten years or more);

- the practical conditions of the gaseous measurement process with an adaptation of the sampling methods (with or without recirculation, purging, etc.) and the methods' alternation in line with the leak's characteristics and flow rate.

Directly measuring the gas flux at the ground/air interface is one of the most efficient ways to perform the monitoring of gaseous emissions on the surface of $\mathrm{CO}_{2}$ storage sites.

The INERIS accumulation chamber method has been improved to measure low and very low fluxes of $\mathrm{CO}_{2}$. These metrological and operational characteristics have been checked and validated by tests performed in a laboratory and on a test rig, as well as through field measurements taken under real conditions at sites that naturally release $\mathrm{CO}_{2}$.

The tests have shown that the method for measuring the gaseous flux directly has reached full technical maturity and that it can be applied on a practical level to detect and monitor $\mathrm{CO}_{2}$ and methane emissions on the ground's surface.

The two methods that were tested as part of the ANR GeoCarbon Monitoring program, even though they are still perfectible and require a certain number of further developments as mentioned previously, are already operational and available for integration into the monitoring strategy of future $\mathrm{CO}_{2}$ storage sites.

\section{REFERENCES}

von Arnold K., Weslien P., Nilsson M., Svensson B.H., Klemedtsson L. (2005) Fluxes of $\mathrm{CO}_{2}, \mathrm{CH}_{4}$ and $\mathrm{N}_{2} \mathrm{O}$ from drained coniferous forests on organic soils, Forest Ecol. Manag. 210, 239-254.

Battani A., Deville E., Faure J.L., Jeandel E., Noirez S., Tocqué E., Benoît Y., Schmitz J., Parlouar D., Gal F., Le Pierres K., Brach M., Braibant G., Beny C., Pokryszka Z., Charmoille A., Bentivegna G., Pironon J., de Donato P., Garnier C., Cailteau C., Barrès O., Radilla G., Bauer A. (2009) Geochemical study of natural $\mathrm{CO}_{2}$ emissions in France's Massif Central: How to predict origin, processes and the development of $\mathrm{CO}_{2}$ leaks, Oil Gas Sci. Technol. Topical issue: $\mathrm{CO}_{2}$ Storage in the Struggle against Climate Change (in press).

Besnard K., Pokryszka Z. (2005) Gas emission monitoring in a post-mining context, International Conference Post-Mining, Nancy, 16-17 November 2005. 
Denmead O.T. (1979) Chamber systems for measuring nitrous oxide emissions from soils in the field, Soil Sci.Soc. Am. J. 43, 88-95.

Charmoille A., Pokryszka Z., Bentivegna G. (2008) Développement des méthodes de suivi géochimique en phase gazeuse à la surface des sites de stockage géologique du $\mathrm{CO}_{2}, 22^{e}$ Réunion des Sciences de la Terre, 21-24 April 2008, Nancy.

Christensen S. (1983) Nitrous oxide emissions from the soil surface: continuous measurement by gas chromatography, Soil Biol. Biochem. 15, 4, 481-483.

Cortis A., Oldenburg C., Benson S. (2008) The role of optimality in characterizing $\mathrm{CO}_{2}$ seepage from geologic carbon sequestration sites, Int . J . Greenhouse Gas Control 2, 640-652.

Fabriol H., Becquey M., Huguet F., Lescanne M., Pironon J., Pokryszka Z., Vu Hoang D. (2007) On-going investigations to design the monitoring program for a $\mathrm{CO}_{2}$ storage project in the Parisian basin (France), 6th annual conference on carbon capture and sequestration, Pittsburgh, 7-10 May 2007.

Jury W.A., Letey J., Collins T. (1982) Analysis of chamber methods used for measuring nitrous oxide production in the field, Soil Sci. Soc. Am.J. 46, 250-256.

Lewicki J., Hilley G., Oldenburg C. (2005) An improved strategy to detect $\mathrm{CO}_{2}$ leakage for verification of geologic carbon sequestration, Geophys. Res. Lett. 19, L19, 413.
Mosier A.R. (1990) Gas flux measurement techniques with special reference to techniques suitable for measurements over large ecologically uniform areas, in Soils and the Greenhouse Effect, Bouwman A.F. (eds), pp. 289-301.

Pokryszka Z., Tauziède C. (2000) Evaluation of gas emission from closed mines surface to atmosphere, Environmental Issues and Management Waste in Energy and Mineral Production, Balkema (eds), Rotterdam, ISBN 9789058090850, pp. 327-329.

Raich J.W., Schlesinger W.H. (1992) The global carbon dioxide flux in soil respiration and its relationship with vegetation and climate, Tellus 44B, 81-99.

Reinhart D.R., Cooper D.C., Walker B.L. (1992) Flux chamber design and operation for the measurement of municipal solid waste landfill gas emission rates, J. Air Waste Manage. 42, 8, 1067-1070.

Rouil L., Pokryszka Z., Jamois D. (2000) Estimating atmospheric transfers from contaminated sites. 7th International Conference on Contamined Soil - ConSoil, Leipzig, 18-22 September 2000.

Savanne D., Berne Ph., Cellier P., Laville P., Pokryszka Z., Sabroux J.C., Tauziède C., Tregourès A. (1997) Comparison of different methods for measuring landfill methane emissions, 6th International Landfills Symposium - Sardinia'97, Cagliari, 13-17 october 1997, IV , 81-85.

Final manuscript received in November 2009 Published online in March 2010 or distributed for profit or commercial advantage and that copies bear this notice and the full citation on the first page. Copyrights for components of this work owned by others than IFP must be honored. Abstracting with credit is permitted. To copy otherwise, to republish, to post on servers, or to redistribute to lists, requires prior specific permission and/or a fee: Request permission from Documentation, Institut français du pétrole, fax. +33147527078 , or revueogst@ifp.fr. 